\title{
Novel polymerase spiral reaction assay for the visible molecular detection of porcine circovirus type 3
}

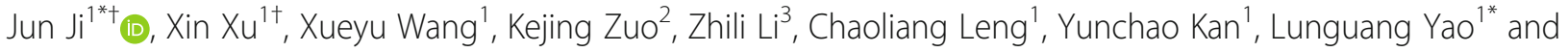 \\ Yingzuo $\mathrm{Bi}^{3}$
}

\begin{abstract}
Background: Porcine circovirus type 3 (PCV3) is a newly emerging circovirus that might be associated with porcine dermatitis and nephropathy syndrome, reproductive failure, and cardiac and multisystemic inflammation. To aid the prevention and control of the infectious disease caused by PCV3, we developed a novel isothermal amplification assay using polymerase spiral reaction (PSR), which allows the visual detection of preserved strains and clinical samples.

Results: This assay precisely amplified the PCV 3 genome with the use of a water bath at $62^{\circ} \mathrm{C}$ for $50 \mathrm{~min}$. The detection limit was found to be $1.13 \times 10^{2}$ copies/ $\mu \mathrm{L}$ by gel electrophoresis or with the use of a visible dye (an indicator comprising phenol red and cresol red). No cross-reaction with other porcine infectious viruses was observed. The detection results for 23 PCV3-positive samples by PSR were in accordance with loop-mediated isothermal amplification (LAMP) assay. The detection rate of the PSR assay for PCV3 positivity of clinical samples was 68/97, which was higher than LAMP assay (67/97).

Conclusions: These results indicated that the PSR assay provides an accurate and rapid method for the detection of PCV3 with high sensitivity and specificity. It is particularly suited for use in a simple laboratory setting without a thermal cycler or gel electrophoresis equipment.
\end{abstract}

Keywords: Molecular detection, PCV3, Polymerase spiral reaction, Visible detection

\section{Background}

Porcine circovirus type 3 (PCV3) is a newly emerging virus associated with porcine dermatitis and nephropathy syndrome, reproductive failure, and multiorgan inflammation, even though its causative role in any of these syndromes has yet to be demonstrated [1-3]. The virus was first reported in pig farms in the USA in 2016 through metagenomic sequencing and was identified to be a new member of the genus Circovirus of the family Circoviridae [4]. This genus also includes porcine circovirus type 1 , which has no clinical manifestations, and porcine circovirus type 2 (PCV2), which has proved to be a significant economic threat for the pig

\footnotetext{
* Correspondence: jijun020@126.com; lunguangyao@163.com

†Jun Ji and Xin Xu contributed equally to this work.

${ }^{1}$ Henan Provincial Engineering Laboratory of Insect Bio-reactor and Henan Key Laboratory of Ecological Security for Water Source Region of Mid-line of South-to-North, Nanyang Normal University, 1638 Wolong Road, Nanyang, Hena 473061, People's Republic of China

Full list of author information is available at the end of the article
}

industry $[5,6]$. Other reports indicated that PCV3 has already been circulating in pig-producing countries for some time before its first detection, although not in the USA, with increasing numbers of infectious cases being reported in Italy, Brazil, Germany, South Korea, and China [7-12]. In addition, there is accumulating evidence that coinfections of PCV3 with other pathogens may be associated with increased pathogenicity in pigs $[1,13]$.

Conventional serological methods have been used to identify PCV3. These methods include an enzyme-linked immunosorbent assay that can accurately detect the viruses, but it can be time-consuming [14, 15]. Molecular methods based on polymerase chain reaction (PCR) assays, both routine and quantitative, have been developed to monitor and detect $\mathrm{PCV} 3$ rapidly and specifically [16-18]. However, these methods require sophisticated thermal cyclers, thereby limiting their usefulness for the practical point-of-care testing of clinical samples. To

(c) The Author(s). 2019 Open Access This article is distributed under the terms of the Creative Commons Attribution 4.0 International License (http://creativecommons.org/licenses/by/4.0/), which permits unrestricted use, distribution, and reproduction in any medium, provided you give appropriate credit to the original author(s) and the source, provide a link to the Creative Commons license, and indicate if changes were made. The Creative Commons Public Domain Dedication waiver (http://creativecommons.org/publicdomain/zero/1.0/) applies to the data made available in this article, unless otherwise stated. 
avoid the need for professional laboratory equipment, isothermal molecular methods for the detection of PCV3 have been developed, including methods based on loopmediated isothermal amplification (LAMP) and recombinase polymerase amplification (RPA) [19, 20]. These isothermal methods have the potential to differentiate PCV3 from other pathogens with high specificity, but neither technique is without imperfections. The LAMP assay for PCV3 detection requires four primers to target at least six sequence regions, strict primer coordination, and a more conserved sequence $[20,21]$. The recombinase polymerase amplification technique needs only one primer pair to accomplish the detection course; however, its reaction products cannot be determined directly by the naked eyes [19].

Polymerase spiral reaction (PSR) is a novel assay technique that requires only one pair of primers, making this assay easier to design and more cost-effective than LAMP assays [22]. Furthermore, the reaction results include a high level of pyrophosphate ion byproducts, which can be directly visualized by adding a suitable $\mathrm{pH}$ indicator. Building on these advantages, we have developed a novel
PSR assay for the detection of PCV3. Here we describe the assay and evaluate its accuracy through the detection of clinical samples.

\section{Results}

Optimal reaction temperature and time for the PCV3 PSR assay

In the agarose gel electrophoresis analyses, a little difference displayed between the reactions from $60^{\circ} \mathrm{C}$ to $65^{\circ} \mathrm{C}$; however, the PSR products at $62^{\circ} \mathrm{C}$ displayed the brightest bands. At this temperature, the band reached its maximum brightness at $50 \mathrm{~min}$. Thus, the optimal PCV3 PSR amplification reaction conditions were found to be using a water bath at $62^{\circ} \mathrm{C}$ for $50 \mathrm{~min}$.

\section{Sensitivity test results}

The sensitivities of the PSR and LAMP assays were compared by detecting their reaction products in agarose gel electrophoresis (Fig. 1). The positivity of the PSR products was also determined by adding a visible dye and observing the color change by the naked eye. The three

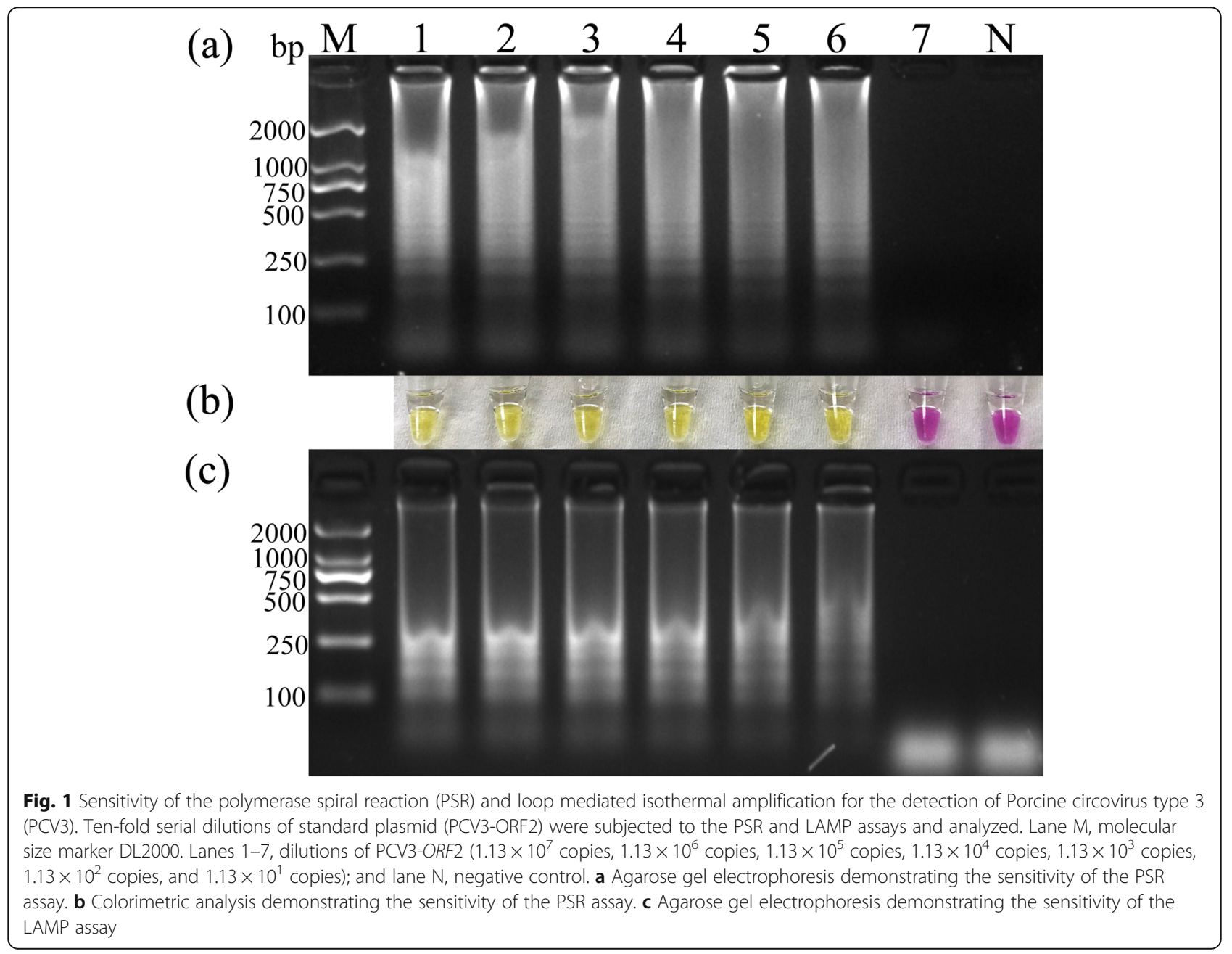


runs were $100 \%$ coincident. Therefore, the detection limits of the PSR and LAMP assays were both $1.13 \times 10^{2}$ copies/ $\mu \mathrm{L}$. In the visible sensitivity analysis, the color of the dye changed from purple-red to yellow at the same detection limit as that determined by agarose gel electrophoresis.

\section{Specificity of the PCV3 PSR assay}

The specificity test confirmed that the PSR assay was specific for PCV3; only PCV3 positive samples showed clear strip-bands, whereas samples positives to other viruses (pseudorabies virus (PRV), porcine reproductive and respiratory syndrome virus (PRRSV), porcine circovirus type 2 (PCV2), classical swine fever virus (CSFV), porcine epidemic diarrhea virus (PEDV) did not. The results were in good agreement with colorimetric analysis of the reactions (Fig. 2), confirming the good specificity of the PCV3 PSR assay.

\section{Application of the PCV3 PSR assay to clinical samples}

There was absolute agreement between the LAMP and PSR assays for the detection of the 23 positive samples. For the clinical tissue samples, the detection rate for PCV3 positivity was as follows: PSR, 68/97 and LAMP, 67/97. The detailed detection results for the clinical samples are listed in Table 1.

\section{Discussion}

Increasing number of reports have suggested that the PSR technique provides a promising isothermal DNA amplification assay that can be used for rapid and lowresource diagnostics, including for detecting some human pathogens and African swine fever virus [23-26]. Cooperated with reverse transcriptase, one-step reverse transcription polymerase spiral reaction (RT-PSR) assay could be used for the rapid detection of porcine epidemic diarrhea virus (PEDV) [27]. In this study, the PCV3 PSR assay displayed similar detection limit with the LAMP assay; it also displayed remarkable accuracy with good specificity for positive samples. The PCV3 PSR assay was most effective at $62^{\circ} \mathrm{C}$; however, the products amplified at all the temperatures tested $\left(61^{\circ} \mathrm{C}-\right.$ $65^{\circ} \mathrm{C}$ ) displayed remarkable results on agarose gel electrophoresis, making this assay practical for use in basic laboratories with low-precision incubating equipment, such as water baths. The reaction time of the PCV3 PSR assay was approximately only half of the time required for conventional PCR and other PCR-based methods. The visible analysis method for the PSR reaction using a $\mathrm{pH}$ indicator without electrophoresis and gel imaging could additionally save time.

A recombinase polymerase amplification (RPA) method combined with a lateral flow strip has recently been developed for visible detection; however, use of the lateral flow

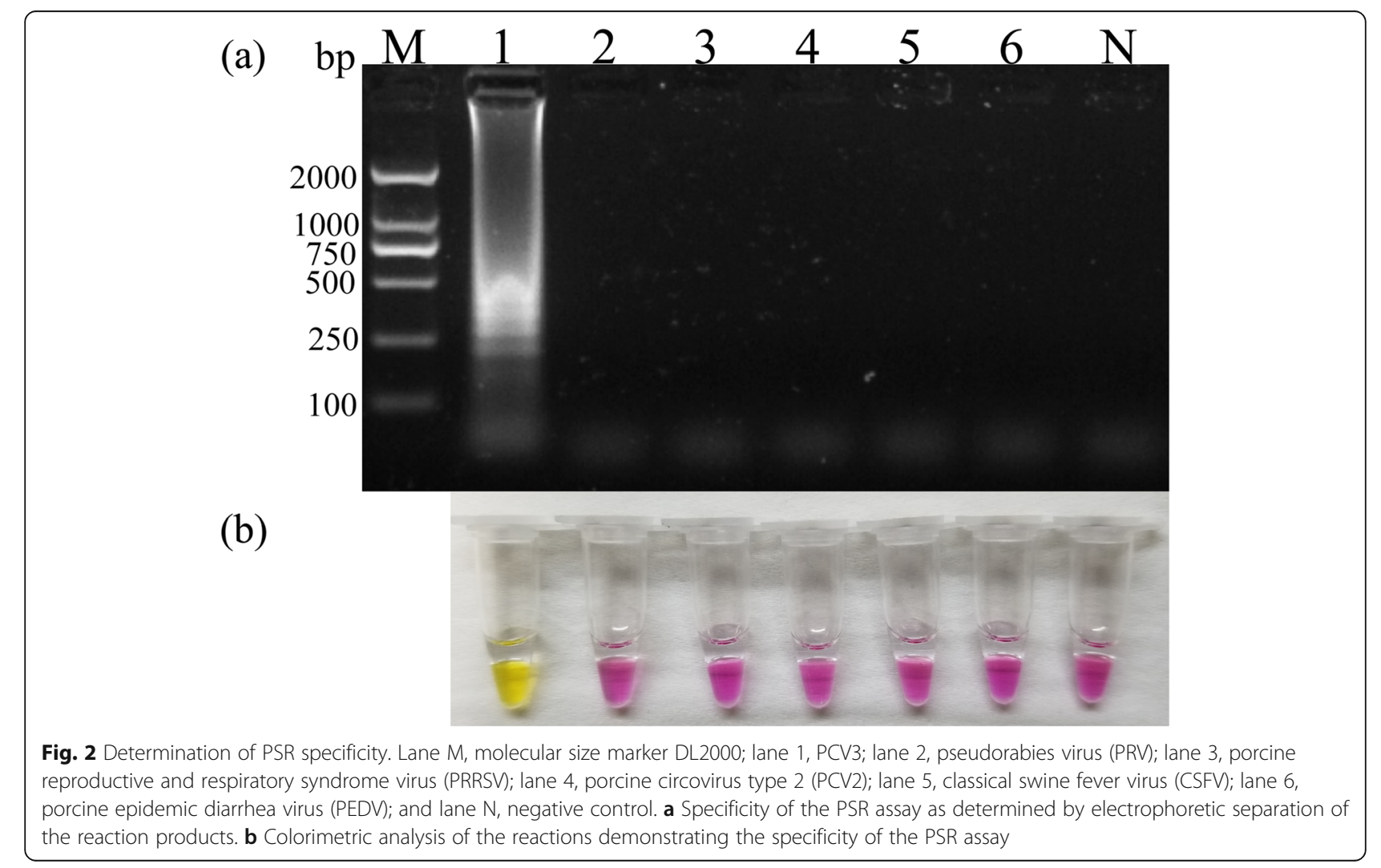


Table 1 Comparison of the detection of PCV3 in clinical samples by polymerase spiral reaction (PSR) and loop-mediated isothermal amplification (LAMP)

\begin{tabular}{|c|c|c|c|c|}
\hline \multirow[t]{2}{*}{ Province } & \multirow[t]{2}{*}{ Date } & \multirow[t]{2}{*}{ Tissues } & \multicolumn{2}{|c|}{ Detection positive rate for different assay } \\
\hline & & & LAMP & PSR \\
\hline Jiangsu & 2017.11 & spleen & $15 / 17^{\mathrm{a}}$ & $15 / 17$ \\
\hline Hunan & 2018.01 & pooled liver and spleen & $13 / 19$ & $13 / 19$ \\
\hline Hubei & 2018.02 & spleen & $21 / 24$ & $21 / 24$ \\
\hline Hubei & 2018.03 & spleen & $6 / 11$ & $6 / 11$ \\
\hline Hunan & 2018.04 & pooled liver and spleen & $4 / 14$ & $5 / 14$ \\
\hline Anhui & 2018.05 & spleen & $8 / 12$ & $8 / 12$ \\
\hline
\end{tabular}

${ }^{\text {a }}$ The two figures indicate the number of positive results/the number of samples

strip increases costs and procedure time [28]. Using SYBR Green I dye with the LAMP assay for PCV3 detection can satisfactorily reveal dissimilarities between positive and negative tubes; however, the dye must be added at the end of the reaction for the inhibitory effect. In these methods, the operations needed for reaction with the lateral flow strip or to add the SYBR Green I dye could increase the risk of false positive results due to aerosol contamination by amplified products [20,28]. Similarly, the high sensitivity of PSR may also contribute to its susceptibility to false-positive results because of the carryover or cross-contamination in the reaction system. Therefore, we using the phenol red dye added before the reaction could reduce aerosol contamination to some extent. To minimize contamination and false-positive results from PSR in practice, sample preparation and PSR reaction and electrophoretic run should be carried out in isolated places. In the detection comparison performed on 97 clinical samples, the PSR assay detected 68 samples positive for PCV3 DNA, whereas the LAMP assays detected67 positive samples, respectively. The PSR assay did not detect PCV3 in 29 of the samples; this was in agreement with the results of LAMP assays. One sample from the Hunan Province was detected as negative by the LAMP assay but was detected as positive by the PSR assays. This missed detection may have been because of a mismatch of primers, suggesting that the PCV3 is undergoing constant evolution and variant. This shows that PCV3 monitoring requires continuous investigation and primer updates. It also demonstrates the practicality of the PSR assay for the clinical detection of PCV3; the assay requires only one pair of primers, making it easier to design when there are mismatches. The high detection rate again confirmed the accuracy and sensitivity of the PCV3 PSR assay.

\section{Conclusions}

In conclusion, this report describes a novel diagnostic test for PCV3 that is deployable in the field. This PSR assay could be developed into a rapid and reliable diagnostic method with the potential for routine use for the detection of PCV3.

\section{Methods \\ Samples}

From winter 2017 to spring 2018, spleens and liver tissues of dead pigs suspected to have been infected with PCV3 were collected from farms of Jiangsu, Hunan, Hubei and Anhui province of China. The samples were washed with phosphate-buffered saline (PBS) and immersed in liquid nitrogen prior to grinding. A 20\% suspension was prepared by adding PBS and then repeatedly freezing and thawing three times. The pretreated tissues were centrifuged at $5000 \mathrm{rpm}$ for $10 \mathrm{~min}$, and $0.2 \mathrm{~mL}$ of the supernatant was taken and maintained at $-80^{\circ} \mathrm{C}$ prior to nucleic acid extraction.

\section{Extraction of viral DNA and RNA}

Viral DNA and RNA were extracted from the samples with a DNA/RNA extraction kit (TransGen Biotech, Beijing, China), according to the manufacturer's instructions. The purity and concentrations of the DNA and RNA were determined by a biological spectrophotometer. The samples were stored at $-20^{\circ} \mathrm{C}$ until use.

\section{Primers design}

Primers used for the PSR assay were designed according to the conserved regions of the ORF2 gene of $\mathrm{PCV} 3$ using Oligo v7.37 (Molecular Biology Insights Inc., Colorado Springs, CO, US). The specificity of primers was preliminarily determined by using NCBI-Blast (https:// blast.ncbi.nlm.nih.gov/Blast.cgi). The primers used for amplification efficiency after the initial screening are shown in Table 2.

\section{Establishing the reaction conditions for PSR}

Based on the optimal constituents identified in previous tests, the PSR reaction was performed in a volume of $25 \mu \mathrm{L}$ containing each primer (forward primer PCV3-SF and backward primer PCV3-SR, both $0.8 \mu \mathrm{M}$ ), a $1.2 \mathrm{mM}$ mixture of dNTPs, $0.8 \mathrm{M}$ betaine, $6 \mathrm{mM} \mathrm{MgSO}_{4}, 8 \mathrm{U}$ of Bst DNA polymerase 3.0 (New England Biolabs, Ipswich, MA, USA), $10 \mathrm{mM}(\mathrm{NH} 4)_{2} \mathrm{SO}_{4}, 50 \mathrm{mM} \mathrm{KCl}, 0.1 \% \mathrm{v} / \mathrm{v}$ Tween-20, and $1 \mu \mathrm{L}$ of template DNA. For the 
Table 2 Primer sets for the polymerase spiral reaction assays (The lower-case $5^{\prime}$ sequence of the forward primer (SF) abstracted from a botanic gene is reverse to the lowercase $5^{\prime}$ sequence of the reverse primer (SR) [22])

\begin{tabular}{lll}
\hline Primer name & Sequence 5'-3' & Position within PCV3-ORF2 $^{\text {a }}$ \\
\hline SF & acgaattcgtacatagaagtatagGTCTTGGAGCCAAGTGTTTGTG & $277-299$ \\
SR & gatatgaagatacatgcttaagcaCTTCATTACCCGCCTAAACGAG & $433-453$ \\
\hline
\end{tabular}

${ }^{\mathrm{a}}$ The primer position is based on the sequence of the Chinese Hubei-610/2016 strain, GenBank accession number: KY354038

colorimetric analysis of the products, $1 \mu \mathrm{L}$ of $\mathrm{pH}$-sensitive dye (comprising $0.025 \mathrm{mM}$ phenol red and $0.08 \mathrm{mM}$ cresol red) was added to each tube. In addition, $25 \mu \mathrm{L}$ of mineral oil was added to prevent the volatilization of the PSR products. The PSR products with repeat target sequences were produced due to different spiral amplification stages as a result of simultaneous Bst DNA polymerase extension at $3^{\prime}$ end and strand displacement at $5^{\prime}$ end [22]. To establish the optimal reaction temperature and time the for PSR assay, gradient optimization was performed first at reaction temperatures of $60^{\circ} \mathrm{C}, 61^{\circ} \mathrm{C}, 62^{\circ} \mathrm{C}, 63^{\circ} \mathrm{C}, 64{ }^{\circ} \mathrm{C}$, and $65^{\circ} \mathrm{C}$ for $60 \mathrm{~min}$, and then for $30,40,50$, and $60 \mathrm{~min}$ at the optimized temperature. For each temperature and time, the reaction product was observed by electrophoresis on $2 \%$ agarose gel, the optimal reaction time and temperature were determined according to the clarity and brightness of the obtained bands.

\section{Sensitivity of the PCV3 PSR assay}

The 645-bp ORF2 gene from a Chinese PCV3 strain was amplified and cloned into the commercial clone vector pMD 18-T (TaKaRa Biotech Corporation, Dalian, China) to create a standard plasmid (PCV3-ORF2). This was used to compare the sensitivities of the PSR and LAMP assays. The limits of detection of the two methods were evaluated by serial 10-fold dilutions of the standard template of the PCV3-ORF2 plasmid from $1.13 \times 10$ to $1.13 \times 10^{7}$ copies $/ \mu \mathrm{L}$, and performed three times to properly assess the detection limit of the two isotherm methods. The LAMP reaction system $(25 \mu \mathrm{L})$ included the same primer sets as reported and $8 \mathrm{U}$ of Bacillus stearothermophilus DNA polymerase. It was performed by using a water bath at $60^{\circ} \mathrm{C}$ for $60 \mathrm{~min}$, as described previously [20]. The amplified DNA product was identified using $2 \%$ agarose gel.

\section{Specificity of the two assays}

The specificity of the PCV3 PSR primers was evaluated by applying the assay to positive samples for reference porcine viruses of a range of DNA types, and $\mathrm{ddH}_{2} \mathrm{O}$ was used as a negative control. These included DNA extracted from PCV2 and PRV and complementary DNA converted from the RNA of CSFV, PRRSV and PEDV using a PrimeScript ${ }^{\text {TM }}$ RT Reagent Kit with a gDNA Eraser Kit (TaKaRa Biotech Corporation, Dalian, China).

\section{Validation with clinical samples}

The diagnostic accuracy of the PCV3 PSR assay was evaluated using viral DNAs of 23 PCV3-positive samples and 97 clinical samples collected from various farms located in Jiangsu, Anhui, Hubei, and Hunan provinces in central China. These samples were analyzed by PSR and LAMP assays simultaneously. The positive detection rates of the two methods were calculated and compared using LAMP as a gold standard.

\section{Abbreviations \\ CSFV: classical swine fever virus; LAMP: loop-mediated isothermal amplification;: PCR: polymerase chain reaction; PCV2: porcine circovirus type 2; PCV2: porcine circovirus type 3; PEDV: porcine epidemic diarrhea virus; PRRSV: porcine reproductive and respiratory syndrome virus; \\ PRV: pseudorabies virus; PSR: polymerase spiral reaction; RPA: recombinase polymerase amplification}

\section{Acknowledgements}

Not applicable.

\section{Authors' contributions}

$X W$, and $X X$ contributed the conception of this study; JJ, XX, YB and LY designed the experiments; $X W, K Z, C L$ and JJ performed the experiments; $Z L$ and $Y B$ acquired samples; XW, YK, and LY drafted the manuscript. All authors read and approved the final manuscript.

\section{Funding}

This study was supported by the National Natural Science Foundation of China (grant no. 31870917), the Scientific and Technological Project of Henan Province (grant no. 182107000040, 182102110084), the Key Scientific and Technological Project of The Education Department of Henan Province (grant no. 18A230012), Key Scientific and Technological Project of Nanyang City (KJGG2018144, KJGG2018069), and Technological Project of Nanyang normal university $(18046,2018 C X 014)$. The funding bodies had no role in the design of the research, the collection, analysis, and interpretation of data, and the writing of the manuscript.

\section{Availability of data and materials}

The datasets used and/or analyzed during the current study are available from the corresponding author on reasonable request.

\section{Ethics approval and consent to participate}

In our research, the clinical samples were submitted to Yingzuo Bi's lab in South China Agricultural University for routine animal health monitoring. Animal experiment was not used in our research. Thus, Ethics approval and consent to participate are not applicable and animal' owners permit us to do this research.

\section{Consent for publication}

Not applicable.

\section{Competing interests}

The authors declare that they have no competing interests.

\section{Author details}

${ }^{1}$ Henan Provincial Engineering Laboratory of Insect Bio-reactor and Henan Key Laboratory of Ecological Security for Water Source Region of Mid-line of South-to-North, Nanyang Normal University, 1638 Wolong Road, Nanyang, 
Hena 473061, People's Republic of China. ${ }^{2}$ Veterinary Laboratory, Guangzhou Zoo, Guangzhou 510642, People's Republic of China. ${ }^{3}$ College of Animal Science, South China Agricultural University, Guangzhou 510642, People's Republic of China.

Received: 30 January 2019 Accepted: 2 September 2019

Published online: 06 September 2019

\section{References}

1. Ku X, Chen F, Li P, Wang Y, Yu X, Fan S, et al. Identification and genetic characterization of porcine circovirus type 3 in China. Transbound Emerg Dis. 2017;64(3):703-8.

2. Klaumann F, Correa-Fiz F, Franzo G, Sibila M, Núñez Jl, Segalés J. Current knowledge on porcine circovirus 3 (PCV-3): a novel virus with a yet unknown impact on the swine industry. Front Vet Sci. 2018;5:315.

3. Ouyang T, Niu G, Liu X, Zhang X, Zhang Y, Ren L. Recent progress on porcine circovirus type 3. Infect Genet Evol. 2019;73:227-33.

4. Palinski R, Piñeyro P, Shang P, Yuan F, Guo R, Fang Y, et al. Novel porcine circovirus distantly related to known circoviruses is associated with porcine dermatitis and nephropathy syndrome and reproductive failure. J Virol. 2016;91(1):e01879-16.

5. Ellis J. Porcine circovirus: a historical perspective. Vet Pathol. 2014;51(2):315-27.

6. Mankertz A, Caliskan R, Hattermann K, Hillenbrand B, Kurzendoerfer P, Mueller B, et al. Molecular biology of porcine circovirus: analyses of gene expression and viral replication. Vet Microbiol. 2004;98(2):81-8.

7. Franzo G, Legnardi M, Hjulsager CK, Klaumann F, Larsen LE, Segales J, et al. Full-genome sequencing of porcine circovirus 3 field strains from Denmark, Italy and Spain demonstrates a high within-Europe genetic heterogeneity. Transbound Emerg Dis. 2018;65(3):602-6.

8. Kwon T, Yoo SJ, Park CK, Lyoo YS. Prevalence of novel porcine circovirus 3 in Korean pig populations. Vet Microbiol. 2017;207:178-80.

9. Shen $H$, Liu X, Zhang P, Wang L, Liu Y, Zhang L, et al. Genome characterization of a porcine circovirus type 3 in South China. Transbound Emerg Dis. 2018;65(1):264-6.

10. Tochetto C, Lima DA, APM V, Loiko MR, Paim WP, Scheffer CM, et al. Fullgenome sequence of porcine circovirus type 3 recovered from serum of sows with stillbirths in Brazil. Transbound Emerg Dis. 2018;65(1):5-9.

11. Saraiva GL, PMP V, JLR F, Bressan GC, Silva JA, de Almeida MR. Evolutionary analysis of porcine circovirus 3 (PCV3) indicates an ancient origin for its current strains and a worldwide dispersion. Virus Genes. 2018;54(3):376-84.

12. Kim SC, Nazki S, Kwon S, Juhng JH, Mun KH, Jeon DY, Jeong CG, et al. The prevalence and genetic characteristics of porcine circovirus type 2 and 3 in Korea. BMC Vet Res. 2018;14(1):294.

13. Ha Z, Xie CZ, Li JF, Wen SB, Zhang KL, Nan FL, et al. Molecular detection and genomic characterization of porcine circovirus 3 in pigs from Northeast China. BMC Vet Res. 2018;14(1):321.

14. Deng J, Li X, Zheng D, Wang Y, Chen L, Song H, et al. Establishment and application of an indirect ELISA for porcine circovirus 3. Arch Virol. 2018; 163(2):479-82.

15. Zhang S, Wang D, Wang Y, Li Z, Zou Y, Li M, et al. Development and application of a baculovirus-expressed capsid protein-based indirect ELISA for detection of porcine circovirus $3 \mathrm{lgG}$ antibodies. BMC Vet Res. 2019;15(1):79.

16. Chen GH, Tang XY, Sun Y, Zhou L, Li D, Bai Y, et al. Development of a SYBR green-based real-time quantitative PCR assay to detect PCV3 in pigs. J Virol Methods. 2018;251:129-32.

17. Li X, Qiao M, Sun M, Tian K A duplex real-time PCR assay for the simultaneous detection of porcine circovirus 2 and circovirus 3. Virol Sin. 2018;33(2):181-6.

18. Xu PL, Zhang Y, Zhao Y, Zheng HH, Han HY, Zhang HX, et al. Detection and phylogenetic analysis of porcine circovirus type 3 in Central China. Transbound Emerg Dis. 2018;65(5):1163-9.

19. Wang J, Zhang Y, Zhang R, Han Q, Wang J, Liu L, et al. Recombinase polymerase amplification assay for rapid detection of porcine circovirus 3 . Mol Cell Probes. 2017;36:58-61.

20. Zheng S, Wu X, Shi J, Peng Z, Gao M, Xin C, et al. Rapid specific and visible detection of porcine circovirus type 3 using loop-mediated isothermal amplification (LAMP). Transbound Emerg Dis. 2018:65(3):597-601.

21. Park YR, Kim HR, Kim SH, Lee KK, Lyoo YS, Yeo SG, et al. Loop-mediated isothermal amplification assay for the rapid and visual detection of novel porcine circovirus 3. J Virol Methods. 2018;253:26-30.
22. Liu W, Dong D, Yang Z, Zou D, Chen Z, Yuan J, et al. Polymerase spiral reaction (PSR): a novel isothermal nucleic acid amplification method. Sci Rep. 2017;5:12723.

23. Das A, Kumar B, Chakravarti S, Prakash C, Singh RP, Gupta V, et al. Rapid visual isothermal nucleic acid-based detection assay of Brucella species by polymerase spiral reaction. J Appl Microbiol. 2018;125(3):646-54.

24. Liu W, Zou D, He X, Ao D, Su Y, Yang Z, et al. Development and application of a rapid mycobacterium tuberculosis detection technique using polymerase spiral reaction. Sci Rep. 2018;8(1):3003.

25. Malla JA, Chakravarti S, Gupta V, Chander V, Sharma GK, Qureshi S, et al. Novel polymerase spiral reaction (PSR) for rapid visual detection of bovine herpesvirus 1 genomic DNA from aborted bovine fetus and semen. Gene. 2018;644:107-12.

26. Woźniakowski G, Frączyk M, Kowalczyk A, Pomorska-Mól M, Niemczuk K, Pejsak Z. Polymerase cross-linking spiral reaction (PCLSR) for detection of African swine fever virus (ASFV) in pigs and wild boars. Sci Rep. 2017;7:42903.

27. Wang $X, X u X$, Hu W, Zuo K, Li Z, Kan Y, et al. Visual detection of porcine epidemic diarrhea virus using a novel reverse transcription polymerase spiral reaction method. BMC Vet Res. 2019;15(1):116.

28. Liu L, Wang J, Zhang R, Lin M, Shi R, Han Q, et al. Visual and equipment-free reverse transcription recombinase polymerase amplification method for rapid detection of foot-and-mouth disease virus. BMC Vet Res. 2018;14(1):263.

\section{Publisher's Note}

Springer Nature remains neutral with regard to jurisdictional claims in published maps and institutional affiliations.
Ready to submit your research? Choose BMC and benefit from:

- fast, convenient online submission

- thorough peer review by experienced researchers in your field

- rapid publication on acceptance

- support for research data, including large and complex data types

- gold Open Access which fosters wider collaboration and increased citations

- maximum visibility for your research: over $100 \mathrm{M}$ website views per year

At BMC, research is always in progress.

Learn more biomedcentral.com/submissions 